\title{
Bondades de la oralidad
}

\section{Christian Peña Castro}

\author{
Juez Mercantil del Poder Judicial del Estado de Colima. México
}

cristianpacastro@gmail.com

Recibido: 10/11/2017

Dictaminado: $15 / 02 / 18$

\section{Resumen}

El surgimiento de la oralidad en el sistema de justicia mexicano fue un acierto necesario, pues recuperó una serie de valores jurídico-sociales que han permanecido soslayados por el anterior sistema escrito de impartición de justicia, con la correspondiente reivindicación de la función jurisdiccional de los órganos encargados de ello. Del mismo modo, trajo consigo la ineludible necesidad para el abogado de actualizarse y profesionalizarse bajo una metodología distinta de la tradicionalista- en el ámbito de la oralización de los procesos, que de suyo, acarrean la imprescindible revalorización del actuar social del profesionista del derecho, con la inminente renovación de colegios de abogados que certifiquen la capacidad del jurista en la práctica forense, bajo lineamientos que promuevan y fomenten la ética judicial y la responsabilidad social de los mismos.

Palabras clave: Procesos, acción social, profesionistas, juristas.

\section{Kidnees of Orality}

\begin{abstract}
The emergence of orality in the Mexican justice system was a necessary success, since it recovered a series of juridical-social values that have remained ignored by the previous written system of imparting justice, with the corresponding vindication of the jurisdictional function of the organs in charge of it. In the same way, it brought with it the inescapable need for the lawyer to update and professionalize -under a methodology different from
\end{abstract}


the traditionalist- in the field of oralization of the processes, which of themselves, entail the indispensable revaluation of the social act of the legal professional, with the imminent renewal of bar associations that certify the jurist's capacity in forensic practice, under guidelines that promote and promote judicial ethics and social responsibility of them.

Key words: Processes, social action, professional, jurist.

\section{Sumario}

I. Introducción. II. Diálogo con la sociedad. III. Transparencia. IV. Reivindicación social del poder judicial. V. Ética profesional. VI. Colegiación de la abogacía. VII. Mejora de la enseñanza jurídica. VIII. Conclusiones. Bibliografía.

\section{Introducción}

Derivado de la inminente implementación total de los juicios orales en la materia mercantil, considerando la exposición de motivos relativa a la reforma al Código de Comercio, que “...tiene por objeto simplificar los procedimientos e instaurar totalmente la justicia oral en materia mercantil, con el fin de incentivar el cumplimiento de obligaciones en las transacciones mercantiles mediante procedimientos mucho más eficientes, eficaces y expeditos... " (Peña Nieto: 2016, pag. 2); es menester hacer referencia a las bondades que en el ámbito social representa este cambio en la administración e impartición de justicia; ello en relación con la imperiosa necesidad que la judicatura tiene de brindar una sólida respuesta a una sociedad que cada vez es más exigente de sus derechos.

Sin embargo, a fin de conseguir lo anterior, debemos primero sortear los problemas que actualmente permean a prácticamente todos los órganos de justicia en el país: la saturación de asuntos pendientes por resolver; la aglomeración inhumana de casos que cada órgano recibe para su tramitación y decisión anualmente; la falta de personal adecuado para hacer frente a la inmensa demanda de justicia que existe en el país; la falta de recursos económicos de los Poderes Judiciales para estar en aptitudes de realizar planeaciones estratégicas a mediano y largo plazo, que mejoren la calidad en la impartición de justicia 
de sus órganos -en algunos casos- y; por supuesto, la aplicación del sistema anacrónico tradicionalmente escrito desde el cual aún se pretende hacer frente a las exigencias de justicia de la sociedad actual; entre otros.

En ese tenor, desde hace varios años, se empezó a gestar a nivel nacional la necesidad de dar solución a los conflictos de los justiciables de una forma más sencilla, ágil y sin trámites engorrosos, en contraposición a los que actualmente se tramitan, que lejos de beneficiar a la óptima resolución de los asuntos -tal y como lo establece nuestra Carta Magna en su numeral 17- entorpecen en demasía la pronta y expedita impartición de justicia, derivado del exceso de formalismos que, como bien se describe en la exposición de motivos de la reforma de referencia, ha dado lugar a la consolidación de la justicia oral en nuestro sistema mexicano; que “...por su naturaleza, es mas ágil frente a la impartida de manera escrita, lo cual toma relevancia debido a la necesidad que tiene el país de que se imparta una justicia cada vez más pronta y expedita en beneficio de las partes y de las instituciones. " (Peña Nieto: 2016, pag. 1). Por lo que, emanado de diversos estudios jurídicos, se llegó a la determinación de oralizar paulatinamente la materia mercantil, ya que:

"No sólo beneficiaría[n] a las partes en economía y seguridad procesal, transparencia y agilidad; se beneficia también al Estado mismo al introducir mecanismos de máxima eficiencia y eficacia en recursos humanos y materiales, al tiempo que incentiva el desarrollo económico empresarial permitiendo la pronta resolución de conflictos mercantiles, así como soluciones alternas sin llegar al final del juicio cuando las partes así lo convengan”. (Peña Nieto: 2016, pag. 3).

Así, la tendencia a oralizar la justicia es, en la actualidad, más una realidad que una utopía-como en algún tiempo se pudo llegar a pensar-, ya que las ventajas que representa la misma, son en gran medida las respuestas que el justiciable dentro del método tradicional no encuentra y que hacen que la sociedad desconfié de las instituciones y procedimientos de procuración y administración de justicia -extendiéndose tal desconfianza a las autoridades y a los operadores mismos del sistema- a más del sentimiento generalizado de injusticia y decepción en el procedimiento por parte de la propia ciudadanía (Peña Nieto: 2016, pag. 1). 
De lo anterior también surge la necesidad de mejorar la enseñanza y el ejercicio del derecho, toda vez que: los foros para la Justicia Cotidiana ${ }^{1}$ detectaron que la mala calidad de los servicios jurídicos es un problema recurrente que repercute en el patrimonio y la situación jurídica de los ciudadanos. La mesa identificó algunas causas que podrían influir en la mala calidad de los servicios jurídicos, las cuales englobó en dos grupos: las relacionadas con la calidad académica de las escuelas de derecho y las vinculadas con el ejercicio de la profesión." (CIDE y UNAM, 2015, p.89).

En esta tesitura, la tradición jurídica escrita, dejará su lugar para que la oral haga frente a las demandas de justicia por parte de la sociedad. Demandas que sólo podrán ser satisfechas mediante la actualización y a la postre certificación de los profesionales del derecho que pretendan internarse en el nuevo sistema de justicia oral; para lo cual se requerirá imperiosamente, de métodos activos de enseñanza, dirigidos a la construcción del aprendizaje, solución efectiva de problemas, desarrollo de habilidades cognitivas, de oratoria, retorica y argumentación, entre otras, así como de un nuevo sentido de responsabilidad ético y social de parte del abogado para con la sociedad.

\section{Diálogo con la sociedad}

De entrada, la sociedad tiene la posibilidad de mantener un diálogo directo con los órganos de impartición de justicia del país, al poder estar en contacto continuo con ellos, mediante su presentación física ante la autoridad que resolverá su conflicto; pues anteriormente era prácticamente imposible que la ciudadanía se enterara de quién o quiénes eran los encargados de resolver su problemática, ya que el hermetismo que provoca el sistema tradicional escrito de impartición de justicia, no permite -en el mayor de los casos- que el justiciable se sienta parte

\footnotetext{
1...el 27 de noviembre de 2014 el Presidente de la República, licenciado Enrique Peña Nieto, solicitó al Centro de Investigación y Docencia Económicas (CIDE) que organizara foros de consulta para elaborar un conjunto de propuestas y recomendaciones para garantizar un mayor y mejor acceso a la justicia. Estos Diálogos por la Justicia Cotidiana, convocados en noviembre de 2015 por el Gobierno de la República, en conjunto con el CIDE y el Instituto de Investigaciones Jurídicas de la UNAM, recogen y desarrollan algunas de las principales recomendaciones de esos foros. (CIDE y UNAM, 2015).
} 
del procedimiento que resolverá su caso en concreto, esto es, el juez y en sentido amplio, el órgano encargado de la administración e impartición de justicia, le son totalmente ajenos a la sociedad. Distantes en cuanto a que desconoce el método a seguir, los tiempos que debe esperar, las formas en que se desarrolla un juicio y las obligaciones y cargas que dependen de su actuar, entre otros aspectos de la relación jurídico procesal, que hacen que el justiciable desconfíe en demasía de los propios actores jurídicos, llámese tanto abogados litigantes como funcionarios judiciales (actuarios, secretarios de acuerdos, archivistas, jueces, etc.), al no comprender la mecánica judicial con que se tramita su asunto, y así - a la postre- encontrarse ante una decisión judicial tardía e poco entendible para sí, a consecuencia de la falta de comunicación efectiva entre la autoridad y la ciudadanía.

Bajo esta premisa, es importante destacar que la oralidad permite ese entendimiento del justiciable con la autoridad, pues el ciudadano se encuentra en presencia del juzgador que va resolver su caso y también ante aquel que no lo hará en específico, pero que tramita y decide otro, pues las audiencias ahora sí son públicas, esto es, cualquier individuo puede asistir a las mismas y darse cuenta de la manera en cómo resuelve el órgano de justicia una problemática, cuál es su tratamiento y decisión, qué tipos de argumentos lógicos-jurídicos utilizan tanto el juzgador como los abogados litigantes para resolver el problema planteado por los justiciables, en el entendido de que la verbalización del proceso, deberá llevarse a través de un lenguaje sencillo, dirigido al común de la sociedad, que no conoce la rebuscada terminología jurídica; lo que naturalmente nos lleva a otro gran beneficio, la transparencia.

\section{Transparencia}

Entendida desde el punto de vista de que los actos procedimentales y netamente jurisdiccionales, están a la luz de todo ciudadano que tenga interés en ellos, no sólo jurídico, ya que, como se mencionó líneas atrás, la actuación de los órganos judiciales será pública, esto es, la tramitación y resolución de los asuntos sometidos a su potestad, está expuesta al escrutinio social, al celebrarse todas las audiencias 
que conforman la nueva estructura de los juicios, en salas de oralidad con libre acceso al público, donde la ciudadanía tiene la posibilidad de conocer quién o quiénes son los facultados para impartir justicia, de qué manera lo hacen, cuáles son las proposiciones y defensas de las partes y finalmente, lo más importante, en qué sentido se resolverá la problemática planteada por los justiciables (actor y demandado) a través de sus abogados; lo que conlleva, necesariamente, a que la sociedad mantenga la confianza en sus órganos de impartición de justicia, en razón a que puede constatar de manera directa la actividad que realizan tanto funcionarios como litigantes y sus correspondientes desempeños.

Lo anterior en contraposición a lo que el sistema tradicional escrito ofrece: un oscurantismo y recelo de las actuaciones judiciales que provocan desconfianza en la sociedad y una presunción inconsciente de corrupción en todos los niveles dentro de la judicatura; ello derivado precisamente, del desconocimiento de los formalismos anacrónicos que permean prácticamente todo el sistema tradicional escrito y al que el justiciable no tiene asequibilidad por ser demasiado técnico y burocrático; lo que nos conduce al siguiente beneficio a tratar: la reivindicación social de los poderes judiciales del país.

\section{Reivindicación social del poder judicial}

Los órganos impartidores de justicia, han sufrido - por décadas-el desprestigio de la ciudadanía, al instaurarse en ésta una consciencia colectiva en el sentido de que la justicia es únicamente para aquellos que tienen posibilidades económicas para comprarla, refiriéndose en términos coloquiales a aquel dicho: "con dinero baila el perro"; que se traduce a que los órganos de justicia únicamente con dadivas y/o sobornos, realizan actos jurídico-procesales (realización de emplazamientos, elaboración de proyectos de acuerdo, préstamo y/o localización de expedientes, etc.) tendentes a la tramitación del juicio de que se trate, y más aún, se ha llegado al extremo de asegurar que todos los jueces son en extremo corruptos y que reciben gratificaciones extras por los asuntos que resuelven, obviamente además de la remuneración gubernamental correspondiente.

Lo anterior debido a que, como ya se puntualizó con anterioridad, la 
sociedad no se encuentra en contacto directo con los órganos impartidores de justicia y, por tanto, desconoce los procedimientos que se siguen en los mismos para la resolución de los conflictos sometidos a la potestad de la autoridad; lo que provoca la apreciación pública de que los funcionarios judiciales, en su gran mayoría, se prestan a actos de corrupción que van desde el más precario -pago por copias- hasta la afirmación de que el servidor público está comprado por el contrario y que por ende dicta resoluciones favorables a las pretensiones que, en su caso, corresponden al cohechador. Percepción a la que el litigante, debo decirlo, ha contribuido en gran medida - por supuesto guardando las proporciones debidas-, toda vez que, lejos de favorecer una sana transmisión de los conceptos jurídicos en los cuales se basa la resolución de cualquier órgano de justicia, suelen patentizar la percepción de corrupción que se tiene: argumentando, para evadir su responsabilidad, que el funcionario se ha "vendido".

Así, esta transición del sistema tradicional escrito al oral, contribuye en gran medida a la Reivindicación Social del Poder Judicial, en cuanto a que el justiciable tiene una mejor percepción de la justicia, y por consiguiente, de los órganos que se dedican a la administración e impartición de la misma, ya que puede verificar y constatar "en carne propia” la función jurisdiccional, al poder observar el desarrollo de los juicios y constituirse en un auténtico fiscalizador de los procesos y del actuar de la autoridad, lo que necesariamente redunda en la confianza que la sociedad espera obtener de sus órganos impartidores de justicia, con la consecuente adquisición de una cultura de la paz que patentice la finalidad esencial de la justicia: la existencia de una sociedad que se desarrolle y desenvuelva dentro de un estado de derecho y que privilegie la solución eficaz de los conflictos suscitados entre particulares; evitando así, la justicia por propia mano, que actualmente es tan recurrida, en razón a la insatisfacción y el desencanto que la ciudadanía aún mantiene de sus órganos de justicia.

\section{V. Ética profesional}

No obstante lo anterior, resulta imprescindible que de la mano de lo citado en el punto que precede, la sociedad, los funcionarios judiciales y los litigantes, 
cambiemos de idiosincrasia, dejemos de un lado la tradición rijosa de nuestro sistema y nos concentremos en la solución eficaz de los conflictos que son sometidos a nuestro escrutinio, aplicando incluso, métodos alternos para la solución de los mismos, como puede ser la mediación, la conciliación, el arbitraje, entre otros, que contribuyan en gran medida al descongestionamiento de los órganos impartidores de justicia y a la correspondiente satisfacción de la ciudadanía al saberse resuelto su problema en un mínimo de tiempo. Sin embargo, lo anterior no puede desarrollarse sino en un ambiente de ética profesional superior al que en la actualidad se percibe, pues resulta aberrante que aún se siga aplicando el famoso dicho: "el que no tranza no avanza", en el argot judicial; cuando debemos ser los primeros defensores de nuestra profesión, tan criticada, pero tan necesaria e importante dentro de la sociedad moderna, pues a los abogados nos incumbe ser los primeros impulsores de los derechos y no los detractores por antonomasia de los mismos.

En ese mismo tenor, es importante puntualizar que en los Diálogos por la Justicia Cotidiana que fueron convocados en noviembre de 2015 por el Gobierno de la República, en conjunto con el Centro de Investigación y Docencia Económicas (CIDE) y el Instituto de Investigaciones Jurídicas de la Universidad Nacional Autónoma de México (UNAM), donde participaron más de 200 personas de 26 instituciones de todos los sectores: investigadores y representantes de la sociedad civil, académicos, abogados, representantes de organismos autónomos y diversas autoridades de los poderes ejecutivo, legislativo y judicial -quienes se reunieron durante casi cuatro meses para diagnosticar y generar soluciones para resolver los principales problemas en el acceso a la justicia-, se concluyó que:

En cuanto a los problemas relacionados con el ejercicio de la profesión, la mesa identificó, por una parte, problemas relacionados con la ética profesional. Este problema tendría múltiples consecuencias, entre las que se mencionaron el que los abogados no tengan impedimento para llevar asuntos sobre los que no tienen capacidad o la falta de mecanismos para la aplicación efectiva de sanciones por mala práctica. En el mismo orden de ideas, la mesa valoró que existen abogados y operadores jurídicos desactualizados e incluso falta información completa sobre el número de cédulas profesionales expedidas y su uso en la práctica de la abogacía en el país. (CIDE y UNAM, 2015, p.89). 
Consecuentemente, resulta primordial que tanto funcionarios como litigantes, profesemos una misma ética profesional que nos conduzca a la celerica y eficaz resolución de los problemas jurídicos que se nos presentan, pues en la medida en que seamos más éticos en nuestra labor, la sociedad nos reconocerá como lo que somos: actores del cambio.

Al respecto, cabe precisar lo que Cruz, Ibáñez, Lozano y Reséndiz (2014, p.14 y 41) refieren: que el abogado es un servidor de la justicia y un colaborador de su administración y que por ello, su conducta ha de estar caracterizada por la probidad, la lealtad y el desempeño digno de su profesión; a más de que el profesionista del derecho, mantiene obligaciones no sólo frente a sus clientes, sus compañeros, jueces y tribunales, poderes públicos y otros profesionales del derecho, sino también frente a la sociedad; pues, en cita de Pablo Bieger:

La profesión de abogado, noble y elevada por la importancia de la misión que le corresponde en la sociedad, es un elemento indispensable para la adecuada impartición de justicia. Corresponde a los abogados el propiciar o contribuir a restablecer la igualdad y armonía entre las personas. Su intervención es necesaria al ser conocedores e intérpretes de los derechos y obligaciones que la sociedad impone a sus integrantes, correspondiendo al abogado enseñar a los demás lo que es justo y lo que no lo es, sirviendo además de dirección y de escudo para la defensa y reclamo contra la arbitrariedad y la injusticia.

Puede decirse que los abogados desempeñan una función al servicio del derecho de enorme importancia social, ya que "auxilian en la resolución de los conflictos sociales, proponiendo al juez las soluciones jurídicamente posibles $-\mathrm{O}$ asesorando a su cliente sobre las mismas-y sobre la probabilidad de que un juez las respalde" (Cruz, Ibáñez, Lozano y Reséndiz, 2014, p. xviii).

\section{Colegiación de la abogacía}

Nuestra sociedad reclama de la abogacía un giro de 360 grados. Está cansada de encontrar profesionistas del derecho sin compromiso social; juristas inmiscuidos en su propia satisfacción y comodidad, ajenos totalmente a la problemática nacional que nuestra propia profesión no ha defendido con diligencia; abogados olvidados 
de su trascendente labor: la de buscar una sociedad más justa y equitativa. Es por ello que surge la inminente necesidad de inquirir otras alternativas para nuestra actuación, tendentes a la profesionalización y colegiación de nuestra disciplina, con el afán de que la sociedad reciba de nosotros un servicio de calidad, tanto profesional como ético, para así poder reivindicar el actuar del jurista ante la colectividad y que éste vuela a ser visto como un pilar de desarrollo de nuestro entorno social; pero para ello, es menester que la ética profesional y la colegiación, permeen nuestra actividad, toda vez que de acuerdo a las conclusiones de los Diálogos por la Justicia Cotidiana, la mesa 4 dedicada a la Mejora de la Enseñanza y del Ejercicio del Derecho:

“Consideró que la prestación deficiente de servicios jurídicos tiene costos como la posible pérdida del patrimonio de las personas que confian la resolución de un problema a una persona que carece de los conocimientos necesarios para tal efecto".

Como otro costo asociado a la prestación inadecuada de servicios jurídicos, la mesa consideró que ésta podría crear "una percepción de desconfianza frente al sistema de impartición de justicia”. (CIDE y UNAM: 2015, pag.90).

De lo anterior, surge la siguiente afirmación: es necesario que la colegiación de abogados sea obligatoria. Ello a virtud de que el crecimiento de los colegios de abogados en el país. Contribuirá en gran medida a que los juristas adoptemos nuevamente nuestro papel dentro de la sociedad, con alta responsabilidad y profesionalismo, ya que, a la fecha, muchos colegas necesitamos de una severa actualización jurídica, no sólo en materia de derechos humanos, que está en boga, derivado de la reciente reforma al artículo primero constitucional y los nuevos criterios que ha asumido la Suprema Corte de Justicia de la Nación y los Tribunales Colegiados de Circuito, que se adecuan al nuevo paradigma de derechos humanos y convencionalidad y que han dado lugar a la Décima Época Judicial en México; sino en general, pues existen en la contemporaneidad muchas deficiencias en los conocimientos jurídicos del profesional del derecho, que hacen que una demanda deficientemente planteada o un inadecuado juicio de valor sobre la sustancia del fondo del asunto o sobre el procedimiento mismo, tengan como desenlace final, el dictado de una resolución de improcedencia, en el mejor de los casos, sobre 
algún presupuesto procesal -que no constituye cosa juzgada- pero, en el peor de los mismos, sobre el fondo del asunto.

En tal sentido, (Cruz, Ibáñez, Lozano y Reséndiz: 2014, XXI) refieren que:

Los colegios de abogados juegan un papel esencial en la garantía de libertad e independencia del abogado, pues solamente la profesión organizada puede contribuir a preservar la dignidad de la profesión, difundir los principios y valores que la constituyen, establecer y promover las mejores prácticas profesionales, identificar plenamente a quienes pudieran apartarse de ellas, aplicar las sanciones que pudieran ser procedentes y responder ante las presiones indebidas que pudieran impedir el correcto ejercicio profesional de cualquiera de sus integrantes, lo que lleva y exige necesariamente la colegiación obligatoria.

Por ello, es trascendente que el abogado tome consciencia de que su actuar profesional, repercute imprescindiblemente en la conciencia colectiva de la sociedad, pues lo que está en juego dentro de un litigio, generalmente, no es únicamente el prestigio del abogado litigante, sino el patrimonio y la vida, en su más amplia concepción, del ciudadano que confía en que el profesional del derecho sea un personaje capaz y letrado, pero sobre todas las cosas, ético.

Ético en sus postulados, honrado en su actuar y lo más importante, sincero en sus expectativas jurídicas del asunto, sin engaños ni artificios tendentes a sacar el mayor provecho económico de la situación, sin la más mínima consciencia de que quien tiene como cliente es un ser humano, que es parte integrante de una sociedad ávida de justicia y anhelosa de que sus problemas se resuelvan sin necesidad de recurrir a la violencia, ni al tráfico de influencias, ni al cohecho, ni a ninguna otra que no sea la vía legal correspondiente.

En tales circunstancias, surge la necesidad y el deber del abogado de mantener sus conocimientos jurídicos actualizados en beneficio de la propia sociedad, quien demanda una previa calificación, en este caso, por parte del colegio de abogados, que tendría la misión de evaluar a los profesionales del derecho a fin de expedir la certificación correspondiente a aquel que cumpla con los puntajes mínimos necesarios o con los parámetros existentes para ello, a fin 
de poder actuar dentro de un procedimiento litigioso (Cruz, Ibáñez, Lozano y Reséndiz; 2014, pag. 39).

Al día de hoy, un profesionista que haya obtenido el título y la cédula profesional, puede apartarse del ejercicio profesional por varios años y retornar a él sin ajustarse a requisito alguno, esto es, nada le impide ofrecer sus servicios sin la correspondiente actualización de sus conocimientos, e incluso, puede además incurrir en errores, conductas irregulares y faltas graves, sin que ello le acarre consecuencia alguna respecto de su ejercicio "profesional" (Cruz, Ibáñez, Lozano y Reséndiz: 2014, pag. X).

Por tanto, en palabras de Cruz, Ibáñez, Lozano y Reséndiz: 2014, XI y XII):

"Sin duda, el establecimiento de la colegiación obligatoria propiciaría el gran cambio que se hace necesario para la modificación de las condiciones del ejercicio profesional, pues de ese modo sería la profesión organizada la que podría determinar cuáles son las mejores prácticas profesionales, la que llevaría a cabo el control y vigilancia de los profesionistas, la que podría propiciar los medios de actualización de conocimientos y fomentar el desarrollo profesional".

\section{Mejora de la enseñanza jurídica}

De lo anterior, resulta importante, necesaria e imprescindible una mejora en el método de estudio del derecho. Por siglos, específicamente desde el XVII, el derecho se ha "transmitido" -si podemos llamarlo así- mediante una exposición Magisterial del letrado o docto en la materia, hacía un alumnado que permanece -a la fecha- pasivo respecto del conocimiento que recibe, pues aún en la actualidad, los maestros mantienen a sus alumnos sentados en sus pupitres en espera de lo que ellos van a argumentar sobre las materias del derecho, ilustrándolos mediante dogmas previamente establecidos por los propios profesores y desde su muy particular punto de vista, y así pretender que el alumnado "entienda" y reproduzca fielmente lo que para el maestro es importante "aprender" del derecho, utilizando prácticamente como única forma, la memorización de los conceptos, procedimientos, esquemas e incluso articulados; cuando pedagógicamente se ha 
considerado -desde hace varios años- que dicha metodología resulta inviable para una debida significación del conocimiento que potencialice las virtudes del individuo, ya que "[...] los fines de la enseñanza contemporánea, [están] enfocados a la comprensión y la habilidad de aplicar activamente lo aprendido." (López Betancourt y Polanco Braga: 2011, pag. 3).

Al respecto, en los Diálogos por la Justicia Cotidiana se consideró:

"Que una posible causa en los problemas de calidad académica podría ser planes de estudio y requisitos de titulación dispares, que podrían dar lugar a egresados con niveles heterogéneos de conocimientos. También consideró que, en ocasiones, las materias son impartidas por personal docente desactualizado, además de que la licenciatura en ocasiones no ofrece contacto profesional suficiente o adecuado".

Flores García, citado por López Betancourt y Polanco Braga, (2011: pag.1), refiere que la escuela tradicional del derecho no puede permanecer al margen de la evolución social, ni de los reclamos de la vida moderna; que, al contrario, siempre deberá ir a la vanguardia - dejando en el pasado la enseñanza libresca, repetitiva, acrítica y casi autodidacta del mismo-, empeñada en la búsqueda de la preparación de profesionales eficientes, honestos y con entrega social; al considerar que el país requiere de abogados con un perfil diferente, para que se conviertan en críticos y transformadores del derecho.

En tal sentido, se estima que la formación a corto, mediano y largo plazo de todos los actores involucrados en el nuevo sistema de justicia oral, deberá de potencializar, además de la solidez teórica fundamental, la adquisición de habilidades y destrezas suficientes para el buen desempeño de una inminente práctica procesal oral, pues el eventual éxito de éste y sus principios -en el magno propósito de transformar positivamente el sistema de justicia nacional-depende de ello (López Betancourt y Polanco Braga; 2011, pag. XIII).

Así, dentro de dicho marco, se debe penetrar cada vez más en la esencia del proceso de la enseñanza del derecho -al evitar la aplicación de métodos que conduzcan a la rutina y al esquematismo- favoreciendo la iniciativa, el deseo de saber y el desarrollo de las capacidades de los actuales y futuros profesionistas 
del derecho (López Betancourt y Polanco Braga: 2011, pag. 3).

En palabras de Eduardo López Betancourt y Elías Polanco Braga. (2011, págs. 3 y 4$)$

El método utilizado en la enseñanza del derecho debe ser cientifico y reflejar las leyes objetivas del mundo, las particularidades de la investigación, las leyes de su desarrollo y la esencia del objeto. Es importante responder, en la enseñanza del derecho, las preguntas siguientes: ¿cuál es el método adecuado? y ¿cuál dará mayores resultados y ayudará a lograr un mejoramiento del proceso de enseñanza aprendizaje? [...] El método en la enseñanza del derecho será decisivo para la actividad cognoscitiva de los estudiantes ( $p$. 3 y 4 ).

Finalmente, el maestro Piero Calamandrei, citado por los propios López Bentacourt y Polanco Braga (2011, p.4), refiere que el mejor método para hacer buenos juristas no es el de constreñir a los estudiantes a nutrirse de charlas durante el lapso que -en su caso- dure su capacitación, sino el de habituarlos, en ese tiempo, mediante la ejercitación del pensamiento, a servirse de la propia mente.

\section{Conclusiones}

Es innegable que con la oralización del sistema de impartición de justicia mexicano, se recuperan muchos valores tanto sociales como jurídicos: como la inmediación procesal, la transparencia, la concentración y publicidad de los procedimientos jurisdiccionales, así como la reducción de la corrupción y de los costos y tiempos procesales; sin dejar de lado la inminente confianza que recobra el justiciable al saberse escuchado y correspondido por los órganos encargados de la administración e impartición de justicia, con la tocante dosis de responsabilidad social que imprescindiblemente despuntará en el actuar del jurista comprometido con su inestimable labor judicial, misma que -de inicioserá paulatinamente fiscalizada por la propia ciudadanía y por los colegios de abogados, que necesariamente tendrán que organizarse y normarse de mejor 
manera, para así poder atender -con diligencia- las exigencias sociales que actualmente requiere la abogacía.

Sin embargo, las anteriores bondades, no tendrán lugar si los actores jurídicoprocesales del nuevo sistema oral de impartición de justicia, no se preparan y capacitan adecuadamente para afrontar los nuevos retos que representa este cambio, toda vez que, si bien la oralización per se, contribuye en gran medida a la solución más eficaz de los asuntos; resulta imprescindible que aquellos que le darán vida al juicio oral, sean juristas verdaderamente capaces de solventar las exigencias que el propio sistema demanda de ellos, esto es, que cuenten con las habilidades profesionales necesarias para una exitosa practica forense oral; lo que sin duda no podrá ser, sin una mejora sustancial en la enseñanza del derecho, que vaya encaminada al desarrollo de la oralidad, la retórica, el discurso efectivo, el control de emociones -verbigracia: el pánico escénico-, la solución alterna de los conflictos, entre otros, que armonicen con un inminente sentido ético y social que revalorice la práctica jurídica del país.

\section{Bibliografía}

Peña Nieto, Enrique. (2016) [1]. Iniciativa de Reforma (Código de Comercio [Juicios Orales]). Consultado el 06 de junio de 2017, en Presidencia de la República. Disponible en Sitio web: https://www. gob.mx/cms/uploads/attachment/file/87913/JUICIOS_ORALES MERCANTILES.pdf

Peña Nieto, Enrique. (2016) [2]. Iniciativa de Reforma (Justicia Cívica). Consultado el 11 de junio de 2016, en Presidencia de la República. Disponible en Sitio web: http:/www.gob.mx/cms/uploads/ attachment/file/87529/JUSTICIA_C_VICA_E_ITINERANTE.pdf

Ferreyra de la Rúa, Angelina. (2008). Oralidad y Descongestión en los Procesos Laborales, Administrativos, Civil, Agrario, entre otros. Colombia: Librería Jurídica Sánchez R. Ltda.

Cruz Barney, Óscar; Ibañez Mariel, Felipe; Lozano Díez, José Antonio; Reséndiz Núñez, Cuauhtémoc. (2014). Lineamientos para un 
Código Deontológico de la Abogacía Mexicana. México: Instituto de Investigaciones Jurídicas (UNAM).

López Betancourt, Eduardo y Polanco Braga, Elías. (2011). Juicios orales en materia civil. México: IURE editores.

Castillo Lara, Eduardo. (2013). El juicio Oral Mercantil. México: Limusa.

Rousseau, Juan Jacobo. (2012). Emilio o de la Educación (21 ${ }^{\mathrm{a}}$ ed.). México: Porrúa.

Moreno Sánchez, G. (2009). Algunas propuestas para logar los beneficios de la oralidad en los procedimientos familiares. En: M.A. Magallón Gómez (coord.), Juicios Orales en Materia Familiar (pp. 143-160). México: Instituto de Investigaciones Jurídicas (UNAM).

Pérez Carbajal y Campuzano, H. (2009). Análisis de la viabilidad de establecer el juicio oral en materia familiar. En: M.A. Magallón Gómez (coord.), Juicios Orales en Materia Familiar (pp. 195-221). México: Instituto de Investigaciones Jurídicas (UNAM).

Centro de Investigación y Docencia Económicas (CIDE) e Instituto de Investigaciones Jurídicas de la UNAM (2015). Diálogos por la Justicia Cotidiana. Diagnósticos conjuntos y soluciones. "Mesa 4, Mejora de la Enseñanza y del Ejercicio del Derecho”. Consultado el 06 de junio de 2017, en Presidencia de la República. Disponible en Sitio web: https://www.gob.mx/cms/uploads/attachment/file/83995/ DIALOGOS_POR_LA_JUSTICIA_COTIDIANA.pdf 